\title{
El Congreso por la Libertad de la Cultura y su apoyo a la disidencia intelectual durante el franquismo
}

\author{
Olga GLONDYs \\ GEXEL, Universidad Autónoma de Barcelona \\ oglondys@yahoo.es
}

Recepción: 13 de enero de 2015 / Revisión: 10 de febrero de 2015

Aceptación: 5 de abril de 2015 / Publicación: Diciembre de 2015

\section{RESUMEN}

El artículo reconstruye los principales aspectos de la labor del Congreso por la Libertad de la Cultura entre la oposición antifranquista del interior. Se describen las circunstancias políticas que motivaron la fundación del Comité Español (1959-1977), así como las principales características de esa célula intelectual antifranquista. El artículo indaga en los objetivos ideológicos y políticos de la actividad del Congreso por la Libertad de la Cultura entre las elites intelectuales y culturales disidentes durante el tardofranquismo. Nos concentramos especialmente en el capítulo que atañe a la ayuda directa dispensada por el Congreso por la Libertad de la Cultura a los intelectuales y artistas españoles mediante la concesión de becas de libros y bolsas de viaje a través del Comité d'Ecrivains et d'Editeurs pour une Entraide Européenne. Reconstruimos asimismo los nombres de los principales beneficiarios españoles de esas ayudas, así como la principal problemática vinculada al desarrollo del programa. El análisis histórico se apoya en documentos procedentes de diversos archivos nacionales e internacionales.

Palabras clave: Guerra Fría Cultural, Congreso por la Libertad de la Cultura, oposición antifranquista, intelectuales, Comité d'Ecrivains et d'Editeurs pour une Entraide Européenne, España, siglo XX.

\section{The Congreso por la Libertad de la Cultura and its support of Intellectual Dissidence during Francoism}

\begin{abstract}
This article reconstructs the principal aspects of the work of the Congreso por la Libertad de la Cultu$r a$ among the anti-Francoist opposition of the inlands. The political circumstances that motivated the foundation of the Spanish Committee (1959-1977) and the principal characteristics of this intellectual anti-Francoist cell are described. The article inquires about the ideological and political objectives behind the activities of the Congreso de la Libertad de la Cultura among the dissident intellectual and cultural elites during the late years of Francoism. Special attention is paid to the direct aid given by the Congreso por la Libertad de la Cultura, to Spanish intellectuals and artists by way of book and travel grants, conceded through the Comité d'Ecrivains et d'Editeurs pour une Entraide Européenne. A list of the names of the principal Spanish beneficiaries of this aid has also been reconstructed, as well as the principal issues tied to the development of the program. The historical analysis is based on documents from various national and international archives.
\end{abstract}


Keywords: Cultural Cold War, Congreso por la Libertad de la Cultura, Anti-Francoist Opposition, Intellectuals, Comité d'Ecrivains et d'Editeurs pour une Entraide Européenne, Spain, $20^{\text {th }}$ Century.

Sumario: 1. Introducción. 2. El CLC y su actividad en España. 3. Comité d'Ecrivains et d'Editeurs pour une Entraide Européenne. 4. Balance provisional y conclusiones. 5. Anexo: "Relación de las becas otorgadas a proyectos de libros y de las bolsas de viaje". 6. Referencias bibliográficas.

\section{INTRODUCCIÓN}

Tras haber sufrido la tragedia de ambas guerras mundiales y la violencia de los movimientos totalitarios, a mediados del siglo XX Europa se había convertido en un territorio dividido y arruinado económica, política y moralmente. En aquellas coordenadas, a fin de asegurar la principal prioridad de su política exterior, orientada a la contención de la Unión Soviética, pero también en respuesta a las expectativas de amplios sectores de las elites europeas, las autoridades estadounidenses diseñaron un ambicioso y vasto programa dirigido a integrar el Viejo Continente dentro de la Alianza Atlántica. De acuerdo con él, la intelligentsia europea devino el target group de una gran variedad de iniciativas, enmarcadas en la diplomacia pública, la propaganda y otras acciones de influencia de Estados Unidos. En esta línea, se destinó un esfuerzo especial a la promoción de la unificación política y económica de la parte occidental del continente, así como a programas que tenían por objetivo labrar el mayor consenso ideológico posible entre las vanguardias de los países que formarían parte de la Alianza Atlántica.

La Smith-Mundt Act (1948) y la Campaign of Truth (1950) proporcionaron a la administración americana el marco organizativo y los abundantes recursos necesarios para llevar a cabo su ofensiva ideológica, en la que los estadounidenses utilizaron, como principales herramientas, la cultura y la "diplomacia de ideas". Así, mientras que la cultura popular americana inundaría Europa Occidental durante todo el período, las autoridades norteamericanas e instituciones representativas de su sociedad civil desplegarían paralelamente una extensa campaña que tenía por meta combatir el antiamericanismo, así como promover el modelo estadounidense en tanto que sociedad moderna, consumista, tecnológica y democrática. Dicha ofensiva ideológica, constituida por una gran diversidad de esfuerzos dirigidos a influir en el conjunto de los grupos sociales que eran su objetivo, es comúnmente englobada bajo los términos "diplomacia pública" o "propaganda", utilizados de forma alternativa o sinónima, $\mathrm{y}$, en cualquier caso, difíciles de delimitar, sobre todo, si comprendemos esta última ampliamente y no solo en su sentido peyorativo ${ }^{1}$. En realidad, la definición exacta de la "diplomacia pública" se halla lejos de haber conquistado el consenso entre

\footnotetext{
1 El debate terminológico es complejo, y, por ejemplo, Antonio Niño y José Antonio Montero desconfían de la utilización eufemística del término "diplomacia pública" y prefieren emplear la palabra "propaganda" para definir el conjunto de las actividades de influencia de EE.UU. durante la Guerra Fría. NiÑo - MonTERO, 2012 , p. 25.
} 
los especialistas ${ }^{2}$, puesto que ni siquiera existe acuerdo sobre los canales que permitieron encauzar todas las iniciativas en su seno -las dificultades se presentan a la hora de definir las contribuciones a las tareas llevadas a cabo por el Estado por parte de los individuales o las organizaciones no gubernamentales-, ni tampoco sobre sus grupos objetivo -igualmente, no hay acuerdo en que las iniciativas fueran dirigidas exclusivamente a los públicos extranjeros ${ }^{3}-$, y dichos escollos para definir un término dinámico y complejo aún se complican más a raíz de los recientes cambios tecnológicos que han conllevado una radical democratización -vía internet- del mundo de la comunicación ${ }^{4}$. Por nuestra parte, consideramos oportuno seguir manteniendo una diferenciación, a priori, entre la diplomacia pública y la propaganda, porque, pese a que sin duda servían a idéntico objetivo -respaldar el liderazgo estadounidense en el polarizado mundo de la posguerra- el estigma asociado al término "propaganda" podría contribuir a reforzar la interpretación vertical de la Guerra Fría ideológica ${ }^{5}$, y alejarnos, de tal manera, de la apreciación de las intrincadas circunstancias, así como de la multiplicidad de factores implicados en la comunicación multilateral -consensos o rechazos, apropiaciones, conflictos y coincidencias, así como negociaciones de distintas agendas (la de la superpotencia, la de las sociedades de destino, la de los grupos objetivo o de los individuos que integraban la maquinaria de la persuasión...)-; en suma, de todas aquellas interacciones complejas que caracterizaron cada intercambio específico desarrollado en el marco de la diplomacia cultural, la propaganda y las acciones de influencia durante la Guerra Fría.

En la literatura especializada reina, por el contrario, asenso sobre la necesidad de discernir entre, de un lado, los programas que de forma oficial manifestaban su dependencia financiera o institucional de los órganos de poder político o de las organizaciones no gubernamentales norteamericanas, $y$, por otro, de toda una serie de operaciones, llevadas a cabo mediante organismos independientes, que fueron encubiertamente financiados por la Agencia Central de Inteligencia (CIA). Estas últimas ofrecen un amplísimo rango, englobado en la literatura especializada bajo el término covert action, ${ }^{6}$ y, en el campo de la Guerra Fría cultural, abarcaron campañas de información y de propaganda política y cultural, iniciativas dirigidas a la promoción de contactos internacionales y de redes sociales y profesionales, y plataformas de colaboración intelectual -a menudo, a través de centros universitarios o culturales-, además de programas más específicos, de subvenciones directas, destinados a proyectos culturales, individuos y organismos independientes. Las distintas operaciones encubiertas que formaron parte de la guerra psicológica de la CIA fueron muy relevantes en la estrategia de la diplomacia pública estadounidense de la Guerra Fría ${ }^{7}$

2 Nicholas J. Cull, en clave humorística considera que el hecho de que no sepamos definir con exactitud el término "la diplomacia pública", no quiere decir que no podamos seguir utilizándolo. CuLL, 2009, pp. 19-23; compárese también, Kelley, 2009, p. 75.

3 Kelley, 2009, p. 73. Cabe señalar, sin embargo, que la comprensión del término "diplomacia pública" como dirigida exclusivamente a los públicos extranjeros es, sin duda, la más extendida entre los historiadores.

4 SNow, 2009, p. 6.

5 Glondys, 2015, p. 91. Compárese Laville - Wilford, 2006, pp. XIII-XIV.

6 Treverton, 1987; Warner, 1995.

7 Nelson - Izadi, 2009, pp. 335-336. 
y, sin ánimo de repetir sistematizaciones realizadas en otro lugar ${ }^{8}$, cabe señalar que organizaciones genuinamente internacionalistas, como el Movimiento Europeo o el Congreso por la Libertad de la Cultura (CLC), cuyo principal objetivo era reforzar la sociedad civil y movilizar la izquierda no comunista contra la desestabilización estalinista y comunista ${ }^{9}$, no sólo fueron objeto de la financiación encubierta, sino también, como en el caso del CLC -supervisado por los agentes Michael Josselson y John Hunt-, de la infiltración directa de sus cúpulas directivas.

La diplomacia pública de carácter oficial en España -desarrollada mediante los programas de intercambio o de información, los medios de propaganda cultural de servicios exteriores, o la difusión de estudios americanos-, ha sido analizada por diversos especialistas ${ }^{10}$, pero el objetivo del presente artículo es contribuir a paliar el vacío historiográfico que aún persiste en referencia a la acción encubierta estadounidense en el país. Nuestro objetivo es reconstruir un capítulo de la labor del Congreso por la Libertad de la Cultura entre la oposición antifranquista; concretamente el que atañe a la ayuda directa dispensada por dicho organismo a los intelectuales y artistas españoles. A este propósito, se apuntan las principales características, así como líneas de análisis, que, a nuestro entender, definen mejor la labor del CLC hacia España y se aporta la mayor parte de los nombres de los becados por el brazo del CLC bautizado con el nombre de Comité d'Écrivains et d'Éditeurs pour une Entraide Européenne $(\mathrm{CEEEE})^{11}$.

\section{EL CLC Y SU ACTIVIDAD EN ESPAÑA}

El Congreso por la Libertad de la Cultura (1950-1967) -una prestigiosa asociación internacional de intelectuales antitotalitarios, al tiempo que principal organismo de acción encubierta estadounidense en el sector intelectual durante la Guerra Fría-, ha

8 GlOndys, 2012a, pp. 20-23.

9 Wilford, 2008, p. 7.

10 En España, sobre los programas de intercambio escribieron, entre otros: Delgado GómEz-EscALONILLA, 2005, pp. 207-243; 2009a; 2009b, pp. 97-132; Rodríguez JimÉneZ, 2007; León Aguinaga, 2009, pp. 133158. Sobre los “American Studies”, consúltese RodRíGuez JimÉNEZ, 2008; 2010. Hay que señalar asimismo el monográfico dedicado a "La ofensiva cultural norteamericana durante la Guerra Fría", coordinado por Antonio NiÑo, de la revista Ayer, 75/3 (2009), así como la colección de ensayos reunidos en Martín García - Ortiz Heras, 2010. Para una visión sintética y panorámica de la "americanización” de España, véase NiÑo, 2012. Es imposible citar aquí la historiografía del tema, con lo que se sugiere consultar el siguiente repertorio bibliográfico: Delgado - LeÓn Aguinaga, 2011.

11 La reconstrucción de los nombres de los becarios fue posible gracias a la consulta de los siguientes archivos: Archivo General del Congreso por la Libertad de la Cultura y de la Asociación Internacional por la Libertad de la Cultura, depositado en la sección Special Collections de la Regenstein Library. University of Chicago; el Archivo Personal de Michael Josselson, conservado en la Harry Ransom Humanities Center, Universidad de Texas; el Archivo Personal de Pablo Martí Zaro, custodiado por la Fundación Pablo Iglesias (Alcalá de Henares, Madrid) [se trata de un legado aún no catalogado ni inventariado, por lo que nos es imposible referir la concreta ubicación de la documentación citada]; Archivo Personal de Salvador de Madariaga depositado en el Instituto José Cornide en A Coruña y el Archivo Personal de Carlos María Bru Purón [consultado gracias a la generosidad personal del Sr. Bru Purón]. 
sido objeto de varios relevantes trabajos de la historiografia internacional ${ }^{12}$ y una monografía dedicada a reconstruir parte de su labor en el mundo hispánico ${ }^{13}$. El CLC centró su labor en el ámbito de la alta cultura y las elites intelectuales, consideradas como los canales más eficaces para ejercer la influencia política en un combate, como el de la Guerra Fría, en gran parte intelectual e ideológico.

Con todo, el Congreso difícilmente puede ser reducido a la categoría de mera herramienta de la política de influencia norteamericana o de "un brazo de la CIA". La realidad, mucho más compleja, es que este organismo, que prestó apoyo a intelectuales antitotalitarios y disidentes en la oscura época del totalitarismo y ayudó a difundir las libertades individuales y los valores del liberalismo occidental en todo el mundo, desplegó su actividad gracias al compromiso ético y la libre aportación a sus iniciativas de numerosos intelectuales legítimamente preocupados por la crisis política y moral de mediados del pasado siglo. Dispuestos a combatir eficazmente el estalinismo y los regímenes dictatoriales de la posguerra mundial, a menudo eran inconscientes del sustento del CLC por la CIA o, como mínimo, del alcance exacto de los lazos del organismo con Washington; ocultación, por otra parte, necesaria tanto para atraer, por un lado, a colaboradores deseosos de conservar su independencia como, por otro, a colectivos reticentes, en la misma medida que posibilitaba que la actividad del CLC fuera percibida como completamente soberana ${ }^{14}$. En este sentido, la complejidad que atañe tanto a la génesis como la naturaleza del CLC exige, a nuestro entender, que toda su actividad se analice sin perder de vista su doble naturaleza: por una parte, la de organismo vinculado a la acción encubierta estadounidense durante la Guerra Fría, pero, por otra, y también, su dimensión no menos real de plataforma de libre expresión de numerosos intelectuales de la posguerra. Así, si bien parece indudable que la decisión de la CIA de "apadrinar" el CLC durante casi dos décadas estuvo motivada en la intención de la Agencia de utilizar los ideales de los intelectuales antitotalitarios en beneficio de la estrategia norteamericana y los principales objetivos de su política de influencia en el exterior ${ }^{15}$, esto en modo alguno era incompatible con el hecho de que numerosos intelectuales se aprovecharan y beneficiaran de la ayuda del CLC para engrosar sus propios proyectos políticos o culturales. Algunos de ellos, además, llegaron a aportar sus valiosas experiencias para contribuir a las políticas de influencia del organismo, lo que abona la tesis sobre la importancia de los individuos en la formulación de las estrategias ideológicas y pragmáticas utilizadas por las superpotencias ${ }^{16}$. En definitiva, la historia del CLC ofrece numerosos ejemplos de que la participación activa de muchos intelectuales en la Guerra Fría ideológica no obedecía a una cesión acrítica ante la maquinaria propagandística de Washington,

12 Coleman, 1989; Grémion, 1995; Hochgeschwender, 1998; Saunders, 1999; Scott-Smith, 2002; WILFORD, 2003; 2008.

13 Glondys, 2012a.

14 Sсотт-Sмітн, 2006, pp. 85-86.

15 Sсотt-Sмith, 2002, pp. 81-84; WiLford, 2008, p. 83.

16 Como ejemplo puede servir el caso del escritor polaco Czeslaw Milosz y su libro El Pensamiento Cautivo (1951), cuyo moderado tono sirvió para atraer hacia el CLC a relevantes sectores de la izquierda francesa, compárese GLONDYs, 2009, pp. 217-224. Otro ejemplo relevante lo constituye la decisiva aportación de algunos exiliados españoles a las estrategias del CLC en su acción en América Latina. GLONDYs, 2012a, especialmente las pp. 76-78. 
sino que partía de su convicción profunda acerca de la necesidad ética e intelectual ineludible de tomar parte activa en aquel combate entre valores de primera magnitud.

En España, la dictadura franquista constituía una notoria anomalía en el contexto de la Europa Occidental y la problemática de dar salida lo más pacífica y establemente posible a la situación dictatorial despertó una seria inquietud en determinados sectores de las elites políticas estadounidenses. Así, al igual que sucedía en los países que, en la época, fueron bautizados como "el tercer mundo" (América Latina, África...), donde la influencia de Estados Unidos -clave para el mantenimiento de los sistemas dictatoriales- le había granjeado la animadversión de amplios sectores de la oposición, también las filas antifranquistas se caracterizaban no sólo por su sentimiento antiestadounidense, sino asimismo por la atracción que sentían por las soluciones políticas y los valores culturales ofrecidas por el marxismo. En razón a ello, a comienzos de los años sesenta, el diagnóstico realizado, sobre la creciente influencia de los comunistas en la oposición antifranquista y el aislamiento internacional de la oposición moderada, originó la puesta en marcha de diversos programas en el seno del antifranquismo, con el fin de contribuir a la estabilidad de las posteriores transformaciones democráticas, en beneficio de los intereses estadounidenses ${ }^{17}$.

No en vano, la escasa capacidad de persuasión que los programas oficiales estadounidenses tenían sobre la oposición antifranquista de izquierdas había revelado palmariamente las limitaciones de una propaganda gubernamental u oficial "que por sí sola, era incapaz de modificar las actitudes de la gente cuando estas se basaban en realidades políticas evidentes" 18 . Era, pues, sobre todo a aquellos grupos reticentes que debían dirigirse acciones de influencia que discretamente les hicieran gravitar hacia posiciones políticas moderadas y proyectos culturales alejados de la corriente marxista. Finalmente, puesto que dichos esfuerzos hacia la oposición debían realizarse con la precaución de no dañar las privilegiadas relaciones de Estados Unidos con el Régimen ${ }^{19}$, la ventaja de llevarlos a cabo de manera no oficial proporcionaba un argumento adicional a favor. En este contexto, el papel desempeñado por ciertos exiliados, entre los que destacaron Julián Gorkin y determinados líderes políticos del Partido Socialista Obrero Español (PSOE), fue auténticamente importante para atraer el interés de los responsables del CLC hacia la situación vivida en el interior por la oposición antifranquista e inclinarlos a ayudarla efectivamente de manera inteligente, esto es, sin comprometer la percepción externa de su autonomía e independencia política $^{20}$.

El CLC desplegó su acción hacia la oposición antifranquista centrándola en programas que incluyeron la promoción de la colaboración política entre los oposicionistas del interior y los exiliados en tres grandes plataformas: la revista Cuadernos del Congreso por la Libertad de la Cultura (1953-1965) -el magazín del CLC en lengua española-, el grupo constituido alrededor del Centro de Documentación y Estudios, en París (1959-1966) -en colaboración con sindicatos norteamericanos-, y el Comité

\footnotetext{
17 Consúltese la relevante documentación al respecto aportada por Delgado Gómez-EsCALONILLA, 2010; Martín García, 2012-2013.

18 NiÑO, 2012, p. 132.

19 Delgado Gómez-Escalonilla, 2010; Martín Garcia, 2012-2013.

20 GLondys, 2011a.
} 
Español del CLC (1959-1977), establecido en el interior de España ${ }^{21}$. Por lo que hace a nuestro tema, el Comité Español del CLC se constituyó en 1960, tras las conversaciones previas mantenidas en la reunión de Lourmarin de 1959, en la que participaron representantes del CLC, de la Fundación Ford -entre ellos, Shepard Stone, director de su División de Asuntos Internacionales (1954-1967), y el presidente de la misma, Waldemar Nielsen- y algunos destacados intelectuales críticos con el Régimen de Franco: Pedro Laín Entralgo, José Luis López Aranguren, Camilo José Cela, José María Castellet, José Luis Cano y Julián Marías (Dionisio Ridruejo y Lorenzo Gomis, aunque invitados, no pudieron asistir), y en otra reunión fundacional posterior, sostenida en septiembre de 1960, en París. En su totalidad, la financiación del programa ibérico del CLC (los comités español y portugués) fue asegurada por un donativo de la Fundación Ford, realizado en 1958, con destino a posibilitar la acción del CLC en los países dictatoriales del este de Europa y la Península Ibérica. Cabe subrayar, sin embargo, que dicho apoyo financiero -pese a que, sin duda, fue muy relevante- no conllevaba en absoluto ninguna obligación de cumplimiento con la agenda propia de la Fundación Ford en España ${ }^{22}$, y que, en dicha relación, el CLC funcionó exclusivamente como un mero receptor de fondos, que desarrollaba sus propias políticas específicas y sus programas particulares ${ }^{23}$. Sin contradecir nada de lo señalado, cabe, con todo, llamar la atención sobre el hecho de que el particular maridaje entre la Ford y el CLC -la fundación era el principal mecenas del organismo, aparte de la CIAera fiel reflejo de un fenómeno que se daba con frecuencia durante la Guerra Fría; a saber, la colaboración de intereses y agendas particulares y estatales en organismos híbridos, conocida bajo el término State-Private Networks ${ }^{24}$. En nuestro caso, merece la pena señalar que la responsabilidad compartida en el respaldo del rol de Estados Unidos en el conflicto de la Guerra Fría ${ }^{25}$, además de la fe en las mismas estrategias -así como, incluso, la amistad entre Stone y Josselson-, unían a los responsables del CLC y de la Ford, sin olvidarnos tampoco de las fuertes conexiones de la fundación norteamericana con los resortes del poder político de Washington ${ }^{26}$. Finalmente, esa estrecha conexión, que, sin embargo -insistimos-, no suponía borrar los límites entre los distintos actores, explica que, tras la revelación de los fondos de la CIA en 1967, los principales responsables de la Fundación Ford rescataran al Congreso y que este

21 Desde la perspectiva de la Historia intelectual, se refirieron a algunos de los principales aspectos de la actividad del Comité Español los siguientes autores, en orden cronológico: MANGINI, 1987; GRÉMION, 1995; Muñoz i Lloret, 2006; Gracia, 2008a; 2008b, pp. XIII-XCIV; Amat, 2009a, pp. 19-22; 2009b, pp. 55-72; 2010a, pp. 98-101; 2010b. Para la reconstrucción histórica, y el análisis desde la propia perspectiva de la Guerra Fría Cultural, de la labor del CLC hacia España, así como de la participación del exilio español en la actividad del CLC en América Latina, consúltese GLONDYs, 2012a.

22 Llevada a cabo a través del Seminario de Estudios y Publicaciones (SEP); consúltese, al respecto: SANTISTEBAn FernándeZ, 2009.

23 Pese a que existían algunas coincidencias entre el programa de la Ford y el del propio CLC, es inadecuado, por lo tanto, emplear el término: "el Congreso por la Libertad de la Cultura de la Fundación Ford". Ibídem, p. 181.

24 LuCAS, 1999.

25 NiÑo - Montero, 2012, p. 31.

26 Consúltese, a este respecto: Berman, 1983; McCarthy, 1987, pp. 93-105; Bird, 1992; Gemelli, 1998; 2000; Berghahn, 2001; Gemelli - MacLeod, 2003; Parmar, 2012. 
pudiera desarrollar su actividad todavía durante diez años más, de 1967 a $1977^{27}$.

En otro estudio tuvimos ya ocasión de aproximarnos al contexto político de la fundación del Comité Español del CLC ${ }^{28}$, que desarrolló una intensa actividad hasta el año 1977. Según nuestras conclusiones, la ayuda dispensada por el CLC a la oposición intelectual y política tenía como uno de sus principales motivos el afán de contrarrestar la acción del Partido Comunista Español (PCE) desarrollada en amplios sectores del antifranquismo. Tras los sucesos estudiantiles de 1956 y el lanzamiento de la política de "reconciliación nacional" por Santiago Carrillo, en septiembre de 1957, el PCE había obtenido innegables éxitos en su penetración progresiva entre la disidencia, incluido en el sector de los ex falangistas desilusionados. En este punto, es preciso subrayar que, pese a que numerosos intelectuales sostenían relaciones con el partido, de manera que algunos estudiosos apuntan incluso a que "la actividad disidente político-cultural estaba manipulada por el PCE con pocas excepciones en esta época" ${ }^{29}$, aún no conocemos la verdad contrastada sobre la extensión real y los valores financieros implicados en las acciones de influencia del PCE entre la intelectualidad antifranquista. Por lo que hace a las políticas ideológicas del CLC, numerosos escritos publicados en la revista Cuadernos pregonaron -a finales de los cincuenta y comienzos de los sesenta-, con clara vocación de barrer hacia su propio terreno, la misma idea de la reconciliación nacional; eso sí, conteniendo una importantísima diferencia con relación al programa propugnado por el PCE: que dicho diálogo nacional y la construcción de la patria del futuro debían desarrollarse con la incondicional exclusión de los comunistas ${ }^{30}$. Pese a ello, la política del CLC en España no consistiría, a la postre, en entrar en rivalidad directa con las políticas comunistas, y menos aun en una acción de contrapropaganda, sino en una inteligente labor de penetración y de búsqueda de consensos entre diversos grupos de la oposición, algunos de los cuales habían sido, hasta entonces, interlocutores estrechos del PCE.

Entre los principales miembros del Comité Español debemos enumerar a Dionisio Ridruejo, Julián Marías, Enrique Tierno Galván, José Luis Cano, Josep Maria Castellet, José Luis Aranguren, Pedro Laín Entralgo, Marià Manent y Lorenzo Gomis. Su primer presidente fue Laín Entralgo, sustituido luego por Fernando Chueca, mientras que su primer secretario, Castellet, sería reemplazado en 1962 por un cercano colaborador de Ridruejo, Pablo Martí Zaro. Además de los mencionados, cabría citar también a los siguientes miembros del comité: Carlos María Brú Purón, Domingo García Sabell, Raúl Morodo y Joaquín Ruíz Giménez, además de Julio Caro Baroja, José Antonio Maravall, Antonio Menchaca Careaga, Jesús Prados Arrarte, Pedro Altares, José Luis Sampedro, Josep Benet, Albert Manent, Josep M. Vilaseca Narcet, Vicente Ventura, Fernando Vicente-Arche, Jaime García Añoveros, Luis Michelena, Eduardo Chillida, Carlos Santamaría, Antonio Buero Vallejo, Ramón Piñeiro y Miguel Delibes. Aparte de organizar numerosas conferencias, coloquios y seminarios con amplia afluencia de un público ávido de apertura y europeización, el Comité Español del CLC -que posteriormente disfrazaría su actividad como editorial Seminarios y

\footnotetext{
27 GrÉmion, 1998, pp. 137-165.

28 Glondys, 2011.

29 Mangini, 1987, p. 106.

30 GLondys, 2011b, pp. 939-949.
} 
Ediciones, S.A.-, promovió un amplio abanico de iniciativas destinadas a establecer una red de contactos entre las elites culturales de diferentes provincias y las capitales españolas (Madrid, Barcelona). Sin duda, la labor del comité significó una importante contribución a la forja de la conciencia democrática española y la estimulación de la disidencia política en el interior, propósitos ambos al que también sirvieron la concesión de becas de libros y bolsas de viaje, tanto al interior del país como al extranjero, así como la acción de envío de libros y revistas realizada desde la capital francesa. Nacieron, así, nuevas redes que conectaron a las elites antifranquistas con las del resto de Europa, y que coadyuvaron a la colaboración efectiva entre diversas familias de la oposición al antifranquismo y a su apertura al exterior.

\section{COMITÉ D'ÉCRIVAINS ET D'ÉDITEURS POUR UNE ENTRAIDE EUROPÉENNE}

El modelo de trabajo del CLC en España adaptó, en el tema concreto que nos ocupa aquí específicamente -las becas y bolsas concedidas a los intelectuales opositores-, los métodos empleados por el organismo en su acción hacia los países dictatoriales de la Europa Central y Oriental. Con el fin de actuar con más soltura a la hora de conseguir visados y permisos, o realizar envíos -es decir, solventar, en la medida de lo posible, los problemas originados por el Régimen-, el CLC operó en dichos países bajo el nombre de Comité d'Écrivains et d'Éditeurs pour une Entraide Européenne. Este informal comité parisino, fundado en 1957 y supervisado por el influyente miembro del Secretariado Internacional del CLC Konstanty Jelenski -aristócrata y crítico literario polaco-, fue independizado financieramente del Congreso en 1966 y refundado, ese mismo año, como Foundation pour une Entraide Intellectuelle Européenne (FEIE) ${ }^{31}$. En relación a España, fue el poeta francés Pierre Emmanuel -responsable máximo del programa ibérico del CLC y, desde 1966, secretario general de la FEIE-, quien, auxiliado por su asistente personal Roselyne Chenu, obraba como intermediario entre el comité de París y el Comité Español. Es preciso recordar también, finalmente, que en 1975, desvinculada de la Asociación Internacional por la Libertad de la Cultura (IACF), la FEIE sería refundada con fondos de la Ford y sobreviviría hasta 1991, momento de su disolución en Cracovia (Polonia) ${ }^{32}$, tras haber sido el único programa que mantuvo su continuidad después de la desaparición de la IACF en 1977.

El programa español puesto en marcha a través del Comité d'Écrivains et d'Éditeurs pour une Entraide Européenne se dividía en cuatro puntos principales: envío de libros no disponibles en España, concesión de ayudas para viajar por el territorio español (de 50 a 60 dólares cada una), becas de 200 dólares para viajar al extranjero con destino prioritario a intelectuales jóvenes (cantidad que ascendía a 300 dólares en el caso

31 Guilhot, 2006, pp. 379-409, aporta muchos detalles relevantes sobre la creación del CEEEE, especialmente en las pp. 382-387. En el Consejo ("board") del comité encontramos los nombres de Raymond Aron, Heinrich Böll, André Chastel, Nicola Chiaromonte, Georges Friedmann, Livio Garzanti, Philip Toynbee y Lionel Trilling.

32 Sobre el tema específico del Comité y la posterior Fundación, merece la pena destacar, además de la de Guilhot, las contribuciones de BEYLIN, 1977, pp. 212-222, y de JiLEK, 2009, pp. 167-183. 
de beneficiarios séniors), y becas para la realización de estudios (300 dólares para individuales y 400 dólares para colectivos ${ }^{33}$. Al objeto de adaptar estas ayudas a las necesidades de intelectuales disidentes, se planteó también la posibilidad de solicitar una ayuda suplementaria en casos de persecución política. En el anexo, señalamos los nombres de los beneficiarios -algunos de ellos, comunistas-, que nos ha sido posible establecer hasta el momento.

El análisis realizado de la documentación histórica y de las correspondencias cruzadas entre los responsables evidencia que los resultados conseguidos en España -a través del programa específico de las becas y bolsas- eran muy insuficientes e insatisfactorios para París. Dan testimonio de ello varias cartas de Pierre Emmanuel y Roselyne Chenu, dirigidas al secretario del Comité Español, Pablo Martí Zaro. Desde el principio, los resultados del programa se vieron lastrados por la pasividad de los becarios, el incumplimiento de los plazos de entrega, la no elaboración de informes posteriores, la no realización de algunos viajes ya pagados ${ }^{34} \mathrm{y}$ la persistente falta de contacto con algunos de los subvencionados, así como el acentuado nepotismo y clientelismo que -en la opinión de París- primaron a la hora de seleccionar a los beneficiarios. Como consecuencia de todo ello, las becas y ayudas serían gradualmente reducidas; primero, en enero de 1963, posteriormente, en diciembre de 1965, mientras Emmanuel llamaba la atención de los españoles sobre la necesidad de que "les bourses ne doivent pas aller automatiquement aux "clients des membres du Comité". Además, en su correspondencia con Zaro, escrita a veces en tono de exigencia, el francés expresaba su voluntad de tener un mayor conocimiento y control sobre los becarios propuestos por los españoles, lo que justificaba en razón de "la mediocridad de los resultados" ${ }^{35}$. Ya con anterioridad, Emmanuel había propuesto mecanismos que permitían presionar al autor becado a introducir modificaciones en el libro concluido, si este "n'est pas à la hauteur de ce que le Comité en attend" 36 , y exigía tener conocimiento sobre los proyectos presentados "para participar de alguna manera en la selección de los aspirantes" 37 . Lo cierto es que los miembros del Comité Español se mantuvieron en una actitud reacia a aceptar ese tipo de interferencias, pero su posición no se tradujo en mejores resultados del programa. Para el balance general del mismo, salvo algunas honrosas excepciones -como la pionera obra sobre el exilio literario La Narrativa española fuera de España, de José Ramón Marra López-, muchos libros becados nunca se llevaron a término e, incluso en el caso de los terminados, no llegaron a publicarse. Era frecuente, por ejemplo, que los beneficiarios se embolsaran la primera mitad de la cuota y ya no volvieran a dar más noticias sobre el

33 “A report to the Ford Foundation 1960". Archivo Personal de Michael Josselson (APMJ); conservado en Harry Ransom Humanities Center. Universidad de Texas, caja 21, f. 5.

34 Pierre Emmanuel, "Note pour monsieur Hunt", de 27 de octubre de 1961. Archivo General del Congreso por la Libertad de la Cultura y de la Asociación Internacional por la Libertad de la Cultura; Special Collections Research Center, Regenstein Library, Universidad de Chicago (IACF), Serie II, caja 92, f. 9.

35 Carta de Pierre Emmanuel a Pablo Martí Zaro, de 22 de enero de 1963. Archivo Personal de Pablo Martí Zaro (APMZ), custodiado por la Fundación Pablo Iglesias. Alcalá de Henares (Madrid). (Se trata de un legado aún no inventariado, por lo que nos es imposible referir la concreta ubicación de la documentación citada).

36 Carta de Pierre Emmanuel a Enrique Tierno Galván, de 19 de diciembre de 1960. IACF, Serie I, caja 23, f. 7 .

37 Carta de Pierre Emmanuel a Pablo Martí Zaro, de 22 de enero de 1963. APMZ. 
proceso de trabajo. Hubo también casos de honradez, como el de Vicente Gaos, quien quiso devolver la suma que percibió ante la imposibilidad de terminar la obra ${ }^{38}$. Mas otros, como el de Ramón Cajade Rey, quien aunque becado para Francia no hablaba ni pizca de francés, agotaron la paciencia de los responsables de París.

Así, en el documento "Voyage en Espagne", de diciembre de 1965 -anónimo, aunque probablemente escrito por Roselyne Chenu ${ }^{39}$-, se hacía un examen panorámico de la marcha del programa y se proponía suspenderlo o remodelar por completo su funcionamiento. El principal argumento era la muy escasa producción derivada de las becas de libros; hasta el punto que de las veintiséis otorgadas desde 1961, sólo se habían publicado siete obras. Al final, el Comité Español decidió cambiar completamente el reglamento de la concesión de las becas, que a partir de entonces debían ser otorgadas por un Consejo de Gestión, decisión que, en cualquier caso, no impidió el progresivo desmantelamiento del programa (véase el Anexo). Además, los intentos de reforma resultaron claramente perjudicados por el escándalo originado por la obra de Sergio Vilar, becario extraordinario del año 1966, titulada Protagonistas de la España democrática. El libro, editado en París ${ }^{40}$, era un repaso crítico y, a juicio de muchos líderes de la oposición ${ }^{41}$, tendencioso e injusto, de la oposición antifranquista, razón por la cual el Comité Español intentó incluso bloquear judicialmente su distribución en Francia.

Ante una situación globalmente muy poco satisfactoria, en octubre de 1966, Emmanuel propuso oficialmente a Zaro suspender el programa y trasladar su presupuesto a otras actividades del comité ${ }^{42}$, lo que tuvo lugar, efectivamente, a lo largo de $1967^{43}$. Más allá de ello, en una misiva estrictamente personal dirigida a Zaro, de 10 de enero de dicho año, el francés se mostraba descontento e insatisfecho con el trabajo del comité y, en general, con la acción del CLC en España. En su opinión, el Comité Español estaba aislado de las corrientes más vivas y dinámicas del país, y se había convertido en instrumento propio de sus eminentes miembros, que sólo pretendían utilizarlo en su propio beneficio y el de sus colaboradores más cercanos. Emmanuel creía, en fin, que el trabajo del comité debía dejar de seguir "la politique des flatteries réciproques, la politique de papa Noël, les bourses de voyages et de travaux aux petits amis des membres du Comité". La labor del CLC en España -instruía Emmanuel- debía consistir en fomentar el espíritu crítico, la independencia intelectual y el desafío activo de la situación dictatorial existente, en lugar de promover actividades

38 Carta de Pablo Martí Zaro a Roselyne Chenu, de 9 de enero de 1967. APMZ. Para más informaciones sobre el desarrollo del programa, véase GLONDYs, 2014.

39 "Voyage en Espagne (13-14 diciembre de 1965)", probablemente de la autoría de Roselyne Chenu. IACF, Serie II, caja 294, f. 6.

40 Protagonistas de la España democrática: la oposición a la dictadura, 1939-1969. París, Librería Española, 1968. Reeditado el mismo año en Barcelona por la editorial Ediciones Sociales.

41 Carta colectiva de protesta, encontrada en el Archivo Personal de Carlos María Bru Purón. Se ha podido identificar las firmas de Carlos María Bru, Joaquín Satrústegui, Miguel Boyer, Jesús Barros de Lis, Fernando Álvarez de Miranda, Ramón Tamames, Marià Manent, Dionisio Ridruejo, José Vidal Beneyto, Enrique Ruiz García, Pedro Laín Entralgo, Fernando Baeza, Antonio Tovar, José Antonio Maravall, Jose María Gil Robles, Pablo Martí Zaro, Fernando Chueca, José Suárez Carreño y José Prados, entre otras difíciles de descifrar.

42 Carta de Pierre Emmanuel a Pablo Martí Zaro, de 12 de octubre de 1966. APMZ.

43 Una manera de darle cierta continuidad fueron las "Ayudas discrecionales para el trabajo intelectual", descritas por primera vez en octubre de 1967. Para los detalles, consultar GLONDYs, 2014. 
culturales de espíritu autocomplaciente y conservador, más propias de las que integraban la agenda particular de la Fundación Ford en España. Se trataba, en definitiva, de remover las conciencias, de "rendre les Espagnols plus conscients de la situation actuelle de leur pays", de huir del academicismo y conservadurismo, y llevar a cabo una acción intelectual ambiciosa y crítica frente al status quo ${ }^{44}$.

La insatisfacción de los responsables del CLC en lo referente a ciertos aspectos del trabajo en España contrastaba claramente con su positiva apreciación del impacto que la labor del CLC tenía para propiciar la cohesión interna entre las distintas familias de la oposición antifranquista y la moderación política de la misma.

En las conclusiones de otro de nuestros trabajos, apuntamos que, en el caso español, el diálogo y el intercambio intelectual constituyeron el principal medio para conseguir "la sinergia de lo políticamente moderado", al tiempo que garantizaron la apertura hacia nuevos horizontes políticos, culturales y artísticos ${ }^{45}$. Gracias al apoyo del CEEEE, los españoles entraron en las redes intelectuales constituidas por los beneficiarios europeos del organismo, mientras que numerosos miembros del Comité Español pudieron participar en seminarios y conferencias internacionales organizados por el CEEEE y la FEIE. La creación de la comunidad de los becarios del CEEEE tuvo como producto el surgimiento de una red social que posibilitaría intercambiar ideas y experiencias en plataformas internacionales, así como contrastar las consignas propias con las ideas de los demás y, last but not least, entrar en contacto con las corrientes intelectuales de toda Europa. En suma, se trataba de utilizar el intercambio intelectual como vehículo de influencia ideológica. Es en este marco que cabe interpretar las frecuentes invitaciones de los intelectuales españoles a los seminarios europeos, durante los cuales podían entrar en contacto directo con sus contrapartidas procedentes de las dictaduras del bloque oriental, y conocer, de esta manera, "las realidades de la vida bajo regímenes totalitarios de distinta persuasión ideológica" ("to get acquainted with the realities of life under totalitarian regimes of a different ideological persuasion" ${ }^{46}$. Al mismo propósito sirvieron los reiterados esfuerzos de Pierre Emmanuel para que los becarios españoles establecieran relaciones en el exterior bajo la tutela del CLC, porque el objetivo del organismo era "resserer (sic) le tissus des relations entre intellectuels et non pas d'encourager le tourisme solitaire" ${ }^{47}$.

Según un relevante documento ${ }^{48}$, se trataba de crear "plataformas comunes" y relaciones que pudieran conducir a un entendimiento por encima de las diferencias ideológicas o, cuanto menos, suavizar las mismas, combatiendo así la radicalización política, la casi total centralización de la vida intelectual en la península (con dos centros exclusivos: Madrid y Barcelona) y la fragmentación política de la oposición. Se trataba igualmente de promover actitudes proeuropeas y prooccidentales entre los intelectuales españoles, al dotarles de la posibilidad de establecer comunicación con re-

\footnotetext{
44 Carta de Pierre Emmanuel a Pablo Martí Zaro, de 10 de enero de 1967. IACF, Serie I, caja 51, f. 1.

45 Glondys, 2012b.

46 Documentos "IACF" Associates in Spain and Portugal", seguido de "The IACF Iberian Program", sin fecha, pero de comienzos de los setenta. IACF, Serie II; caja 152, f. 5, cit. en Ibídem.

47 Pierre Emmanuel, "Note pour monsieur Hunt", de 27 de octubre de 1961. IACF, Serie II, caja 92, f. 9.

48 "The IACF Iberian Program". IACF, Serie II; caja 152, f. 5. El documento fue analizado con detalle en GLONDYs, $2012 \mathrm{~b}$.
} 
presentantes de la intelectualidad europea. El último fin de la puesta en marcha de esa herramienta del intercambio, o esas "corrientes de contacto" 49 , era ganar ascendiente ideológico sobre los intelectuales de la península y, mediante su concienciación de las situaciones de opresión intelectual sufridas en el bloque comunista, prevenir su tendencia a buscar en esa misma ideología remedio a su propia situación política. Al mismo tiempo, gracias a los contactos con los reconocidos intelectuales occidentales, los intelectuales españoles adquirirían también la posibilidad de abrirse a tendencias más modernas que las estancadas consignas ideológicas que, de forma inevitable, dominaban el ambiente intelectual anormal de la dictadura franquista.

\section{BALANCE PROVISIONAL Y CONCLUSIONES}

La Guerra Fría ideológica se ha convertido en los últimos años en un territorio de gran fertilidad para la emergencia de nuevas perspectivas que pretenden definir las dimensiones exactas y las estrategias de la contención, por el "poder blando" -la cultura, los valores y la ideología- ${ }^{50}$, del comunismo y la difusión del modelo americano. Pese a lo problemático que resulta realizar una valoración epistemológica de cualquier acción de influencia ${ }^{51}$, en el caso que nos ocupa, los datos establecidos a través del análisis de los documentos permiten apreciar el impacto del CLC en la liberalización de la cultura en el tardofranquismo, así como para la cohesión de la oposición intelectual y su moderación política. En relación con ello, un informe dirigido a la Ford confirmaba que el objetivo del "Programa Ibérico de la IACF" era posibilitar que los intelectuales de la península tomasen parte activa en la consolidación del desarrollo de gobiernos democráticos, a la vez que señalaba que su "compromiso con la democracia" dependía precisamente del éxito de los líderes moderados y sus políticas ("moderate leaders and their policies"). En esta línea, los recursos de la Ford -financiadora de la totalidad del Programa Ibérico del CLC-, fueron destinados a "consolidate outward-looking democracy" a través de un diálogo peninsular y europeo, tanto en la esfera política como en la cultural ${ }^{52}$.

Ahora bien, en lo que concierne exclusivamente a su actividad referente a la repartición de becas y bolsas de estudio a través del Comité d'Écrivains et d'Éditeurs pour une Entraide Européenne, el programa español fue, sin duda, modesto si comparamos su dimensión con la inmensa ayuda que el CEEEE y el FEIE otorgaron a los intelectuales procedentes del bloque oriental. El capítulo español de la actividad del CEEEE tampoco fue particularmente exitoso en cuanto a sus resultados en la producción intelectual de la época; no en vano, tal como ya hemos señalado, fue precisamente por los malos resultados de esa inversión que el programa de becas y bolsas fue suspendido. En este caso concreto, parece muy dudoso que la decisión estuviera motivada por razones políticas. Bien que no deja de ser significativo que la fulminante suspensión tuviera lugar poco después de la edición del referido libro de Vilar, la frustración por

\footnotetext{
49 Scotт-Sмith, 2008a, pp. 74-91.

50 NyE, 1990.

51 Abundan sobre este problema, Niño - MonTERo, 2012, pp. 40-46.

52 "Report to the Ford Foundation 1977", pp. 6-7. IACF, Serie II, caja 109, f. 6.
} 
los resultados obtenidos entre los becarios españoles era ya patente, desde tiempo atrás, en la dirección del Congreso y el CEEEE.

Donde, sin embargo, el programa español sí obtuvo éxito, a ojos de sus responsables, fue en el terreno político. Así, según una relevante carta del nuevo director de la Asociación Internacional por la Libertad de la Cultura Adam Watson, gracias a los programas de grants a los intelectuales españoles otorgados durante los años de la dictadura, el organismo había logrado hacerse con su total confianza. De ahí que, a finales de los años sesenta y comienzos de los setenta -periodo de efervescencia política en España-, esas mismas elites buscaran ayuda y asistencia en los responsables de la IACF, lo que tenía, para estos últimos, una doble consecuencia positiva. Por un lado, permitía al IACF apoyarse en la red de elites culturales y políticas necesaria para llevar a cabo las iniciativas del organismo únicamente mediante conductos y medios locales, es decir, sin que pudiera apreciarse, desde fuera, ningún tipo de interferencia extranjera. Por otra parte, colocaba al organismo en una situación inmejorable, muy cerca de prestigiosos sectores que ahora le otorgaban confianza, gracias al auxilio y el interés dispensado hacia ellos durante los años de la dictadura. Concluía Adam Watson al respecto:

The IACF thus has the exceptional opportunity of assisting Spanish democratic intellectuals in their desire to foster a peaceful transition towards a fully-fledged working democracy ${ }^{53}$.

En otras palabras, en la óptica de los responsables de la IACF, la labor en España les había permitido posicionarse, casi imperceptiblemente, en el centro del mainstream intelectual y político, desde donde pretendían contribuir a la estabilidad política de España en su transición democrática. Tal como señalaba también el mismo Watson, el núcleo intelectual agrupado en torno a la IACF iba a complementar el trabajo de moderación política que el PSOE realizaba entre los obreros y los sindicatos, ocupándose específicamente del sector intelectual del país.

Los principales expertos en la historia del CEEEE y la FEIE no albergan duda de que la labor de esos organismos -a través de la "red de influyentes amistades", como llamó a la comunidad de sus becarios el propio Konstanty Jelenski- representaba una estrategia más en el contexto de la Guerra Fría cultural e ideológica. En el caso de estos programas, se trataba de formar a las futuras elites locales, a la vez que de prevenir la participación de intelectuales de prestigio en iniciativas culturales que rondaran los partidos comunistas, tanto si estos se encontraban en el ejercicio del poder hegemónico (la Europa del Centro y del Este) como si constituían las principales fuerzas de oposición a las dictaduras en la Europa meridional. La estrategia ideológica del CLC en España consistió en promocionar el consenso ideológico y la colaboración entre diversas familias de la oposición, la promoción de la actitud de compromiso activo contra la dictadura, y finalmente, la política de auxilio hacia determinados individuos y grupos con el fin de ganarse su colaboración. En la medida en que la red intelectual

53 Carta de Adam Watson a Robert G. Livingston, de German Marshall Fund, sin fecha, comentada con detalle en GLONDYs, 2012b. 
creada a través del Comité Español posibilitó la cohesión de la oposición, además de su apertura al exterior, esas políticas favorecieron la propia resistencia al franquismo y contribuyeron a construir un baluarte a la influencia comunista. Finalmente, al igual que en la Europa del Este, la red de beneficiarios españoles de los programas del CLC acabaría constituyendo, aunque, sin duda, en grado mucho menor, un "réseau informel d'opposition intellectuelle" que contribuyó a la cristalización, el relevo y el enderezamiento de las elites intelectuales en la posterior transición democrática ${ }^{54}$.

Ciertamente, el factor cultural, decisivo a la hora de analizar la evolución democrática de la Europa de la posguerra, es, asimismo, imprescindible en el caso de España; en especial, si se toma en cuenta la intensidad de la labor cultural e ideológica estadounidense hacia diversos sectores de la sociedad española. Si, además, las relaciones internacionales constituyen, en realidad, otra manifestación más de las complejas interacciones entre pueblos e individuos, la perspectiva cultural resulta muy fructífera para la adecuada comprensión de los complejos procesos políticos e ideológicos desarrollados durante la Guerra Fría ${ }^{55}$. No sólo porque las ideas influyen en las soluciones políticas y en las formas de organización de la vida colectiva, sino también porque ideas y valores éticos subyacieron -de una manera muy intensa, inédita en la historia- tras el enfrentamiento de la Guerra Fría, conflicto avant tout, ideológico, entre modelos de sociedad opuestos ${ }^{56}$.

La principal aportación del CLC a la comunidad atlántica consistió, en suma, en identificar, debatir y promover determinadas ideas y valores para respaldar el compromiso de las elites con la defensa de la civilización occidental y la cultura liberal frente a las realidades totalitarias y dictatoriales. Al servicio de este objetivo, el carácter encubierto del apoyo estadounidense permitió al Congreso abarcar con su influencia a grupos especialmente difíciles de alcanzar para los programas oficiales; entre otros, los intelectuales de izquierdas y opositores a las dictaduras neofascistas o militares. La acción del CLC contribuyó a la inclusión de los intelectuales españoles en las redes transnacionales partiendo de la premisa de que "las corrientes de contacto", para utilizar otra vez el término de Scott-Smith, constituían uno de los medios más eficaces a la hora de forjar consensos políticos e ideológicos, y establecer colaboración entre las elites europeas y americanas. Guiados por el afán de reflejar en su justa dimensión las complejidades de la labor del CLC, merece la pena insistir, antes de concluir, en que si bien el organismo sirvió a determinados objetivos dentro de la comunidad atlántica, por lo que se refiere al intercambio de ideas en su seno, así como la construcción de redes intelectuales y procesos culturales, el Congreso devino una operación en igual medida europea que americana ${ }^{57}$. El concreto capítulo español de su actividad aún espera una monografía específica.

54 JILEK, 2009, p. 169.

55 Para una reflexión sintética sobre el "cultural turn" y la re-conceptualización de la historia de la Guerra Fría en las dos últimas décadas, que exige una mayor apreciación de ideas y de ideología en todos los aspectos del estudio del período, compárese: Aubourg - Sсотт-Sмiтн, 2008a, pp. 8-15; Sсотт-Sмiтн, 2008b, pp. 173195.

56 Milosz, 2003, pp. 119-122; Sсотт-Sмiтн, 2008a, p. 75.

57 Sсотт-Sмiтh, 2010, pp. 132-145. 


\title{
5. ANEXO: "RELACIÓN DE LAS BECAS OTORGADAS A PROYECTOS DE LIBROS Y DE LAS BOLSAS DE VIAJE" 58
}

\begin{abstract}
Año 1960
10 BECAS DE LIBROS, cada una de 300 dólares o 1500 francos franceses: Ignacio Aldecoa, José Aumente, I. Fernández de Castro, Ricardo Doménech, José Ramón Marra López, Josefina Rodríguez, Pablo Martí Zaro, Vicente Ventura Beltrán y Julio López Hernández. Esteban Pinilla de las Heras obtuvo 400 dólares (2000 francos franceses) para el libro colectivo La España contemporánea como problema sociológico.

BOLSAS DE VIAJE AL INTERIOR DE ESPAÑA, de 300 francos: Julio López Hernández.
\end{abstract}

\begin{abstract}
Año $1961^{59}$
10 BECAS DE LIBROS, cada una de 300 dólares o 1500 francos franceses: Enrique Tierno Galván: Costa y el Regeracionismo ${ }^{60}$; Esteban Pinilla de las Heras: $L a$ España intermedia ${ }^{61}$; Luis Felipe Vivanco: Las musas y las brujas en la obra de Moratín ${ }^{62}$; José Ramón Marra López: La narrativa española en el exilio ${ }^{63}$; Javier Franco Manera: Veinte años de pensamiento español; César Armando Gómez: Iglesia y Estado en el pensamiento católico contemporáneo ${ }^{64}$; Emilio Ruiz: Estudios económicos de la provincia de Soria ${ }^{65}$, y Joan Fuster, Poetes, moriscos $i$ capellans ${ }^{66}$.

Dos obras colectivas: Problemas culturales y sociales en el desarrollo económico español, dirigida por José Luis Sureda, catedrático de la Universidad de Barcelona (con colaboraciones de Ángel Latorre, Juan Reventós, Alfonso C. Comín, E. P. de las Heras, J. Castellet...), y La Sociedad española actual a través de sus novelistas, diri-
\end{abstract}

58 Cabe señalar que la documentación reunida no ha permitido establecer los datos de edición de todos los libros becados, y lamentablemente, carecemos de los listados de títulos nunca publicados. Para la base documental de este Anexo y los detal les sobre los procesos de selección, consúltese asimismo GLONDYs, 2014.

59 Más tarde resultaría que, de los años 1961-1962, había quedado algo de dinero y se decidió conceder una beca adicional al libro colectivo Problemas culturales y sociales en el desarrollo económico español, coordinado por José Luis Ugarte.

60 Costa y el Regeracionismo. Barcelona. Ed. Barna, 1961.

61 En su obra En menos de la libertad: dimensiones politicas del grupo Laye en Barcelona y en España (Barcelona, Anthropos, 1989) Estebán Pinilla de las Heras señala que el CLC le financió “una gran investigación sobre estructura social española", pero que dado que "este asunto se sale ya del período acotado para este trabajo, no es pertinente hablar de él aquí", p. 189. En cualquier caso, Pinilla medita sobre el concepto de la "España intermedia" en dicha obra, p. 439 y ss.

62 A juzgar por la similitud del título, la beca posiblemente ayudó en la confección de la obra Moratín y la ilustración mágica. Madrid. Taurus, 1972.

63 Narrativa española fuera de España: (1939-1961). Madrid. Guadarrama, 1963.

64 A juzgar por la similitud del título, la beca posiblemente ayudó en la confección de la obra Catolicismo y Democracia. Madrid. Península, 1966.

65 Estudios económicos de la provincia de Soria. Soria. Gráficas Sorianas (Cuadernos SAAS, 2), 1970.

66 Poetes, moriscos i capellans. València. L'Estel, 1962. 
gida por Castellet (con colaboraciones de Francisco Rodón, Joaquín Marco Revilla, etc.) ${ }^{67}$.

4 BOLSAS DE VIAJE AL EXTRANJERO PARA PERSONALIDADES, cada una de 1500 francos:

El ensayista y secretario de Revista de Occidente, Fernando Vela, para París; el poeta Salvador Espriu, a los países del Benelux y Alemania; el escritor Miguel Delibes, para Francia, y el dramaturgo Alfonso Sastre.

10 BOLSAS DE VIAJE AL EXTRANJERO PARA JÓVENES INTELECTUALES, cada una de 1000 francos:

Alfonso C. Comín Ros, para Sicilia; José Agustin Goytisolo, para Italia; Jesús López Pacheco, para Italia; Juan Gomis, para Italia; Ramón Barce Benito, para Alemania. Posiblemente, fueron becados también Víctor Miguel Pérez Díaz, a París; Benito Madariaga de la Campa, a París; Joan Triadu Font, para Italia, y finalmente, el novelista Juan Marsé, a París.

BOLSAS DE VIAJE AL INTERIOR DE ESPAÑA, de 300 francos.

El crítico literario Alberto González Troyano; el novelista Miguel Espinosa; Ángel Fernández Santos (para París [sic]) ${ }^{68}$; Julio Antonio Alonso Serra (a Madrid); el pintor Segundo Castro Olmo (para diversas ciudades de España); el crítico cinematográfico Alfonso García Seguí (para Madrid y Salamanca); la historiadora Angelina García Pérez (para Valencia); el filósofo alicantino José Iborra Martínez (para Madrid); el escritor Guillermo Gudel Martí (para Madrid); Gonzalo Añez Álvarez (para Salamanca); Alejandro Gago Queipo (para Madrid).

\section{Año 1962}

10 BOLSAS DE VIAJE AL EXTRANJERO PARA JÓVENES INTELECTUALES, cada una de 1000 francos:

Jordi Carbonell, para Gran Bretaña; Arturo Pina González, para Londres; Julio Martín Caro; Alfredo Ramón, para Bélgica y Holanda; Emilio Sánchez Arteaga (Emilio Salcedo), para Francia, Suiza, Bélgica y Holanda; Celso Montero Rodríguez, para París ${ }^{69}$; Manuel Martínez Azaña, para París; el pintor Francisco Moreno Galván, para Italia, y Rafael Santos Torroella, para Viena.

4 BOLSAS DE VIAJE AL EXTRANJERO PARA PERSONALIDADES, cada una de 1500 francos:

El escritor Joan Oliver, para Italia; la novelista Rosa Chacel, para París; el escritor Carlos Bousoño, para México, e Ignacio Aldecoa, para Varsovia, París y Bonn.

5 BECAS DE LIBROS, cada una de 400 dólares o 2000 francos franceses:

\footnotetext{
67 A las alturas de noviembre de 1961, ambas obras colectivas dirigidas por Sureda y Castellet, recibieron, respectivamente, cantidades adicionales de 3200 y 2500 nuevos francos, sin embargo, aún a la altura del diciembre de 1965 estaban en proceso de preparación; la primera, bajo una nueva dirección de Luis Ángel Rojo, en Glondys, 2014.

68 Documento "Tercera y última relación de viajes interiores para 1961". IACF, Serie II, caja 10, f. 2.

69 Finalmente, Montero Rodríguez no pudo salir de España, por la prohibición de su obispo, pero, de todas formas, el Comité le envió el dinero en espera de "mejores tiempos". Carta de Pierre Emmanuel al abad Celso Montero Rodríguez, de 26 de octubre de 1962. IACF, Serie I; caja 34, f. 4.
} 
Miguel Espinosa, para el libro La reflexión política -esta bolsa será anulada por unanimidad, por los problemas de comunicación persistentes con el autor-; Vicente Gaos, con Poesía de nuestro tiempo -libro no llevado a término-; Raúl Morodo, con Estado Liberal y Estado Social de Derecho; Alfonso Carlos Comín, para Trabajo y Técnica Industrial en el Sur de España ${ }^{70}$, y José María López Piñero, para Medicina y sociedad en la España del siglo XIX ${ }^{71}$.

\section{BECAS ADICIONALES}

Fermín Solana, para el libro El señoritismo. Ensayo de tipología social.

Raúl Morodo: 1000 francos de ayuda directa por parte del Comité de París, debido a su situación política.

\section{Año 1963}

5 BECAS DE LIBROS, cada una de 4000 francos franceses, según los cambios introducidos en enero de $1963^{72}$ :

José Jiménez Lozano, para el Panorama del anticlericalismo español (a la altura de junio de 1966, aún pendiente de entregar) ${ }^{73}$; Joaquín Molas, para el libro Literatura y Sociedad (aproximación a la literatura catalana moderna: 1500-1962) (a la altura de junio de 1966, aún pendiente de entregar) ${ }^{74}$; Francisco Pérez Gutiérrez, para el libro Símbolo y objeto (al final, a comienzos del año 1967, finalmente renunciaría a su bolsa ${ }^{75}$ ); Emilio Salcedo (Emilio Sánchez Arteaga), para confeccionar una biografía de Unamuno, Vida de don Miguel ${ }^{76}$, y Vicente Ventura Beltrán, para el libro titulado provisionalmente Problema diferencial del País Valencià (a la altura de junio de 1966, aún pendiente de entregar).

BOLSAS DE VIAJE AL EXTRANJERO PARA JÓVENES INTELECTUALES, cada una de 3000 francos, según el nuevo reglamento introducido en enero de 1963: Ángel Crespo y Pérez, para Italia; Francisco Gracia Guillén, para Viena; Albert Manent, e Ignacio Sotelo Martínez, para Alemania. Se recomendaba para el año siguiente la propuesta de Antonio García Dorado. También recibieron financiación Víctor

70 A juzgar por la similitud del título, la beca posiblemente ayudó en la confección de la obra España del sur: aspectos económicos y sociales del desarrollo industrial de Andalucía. Madrid. Tecnos, 1965.

71 Medicina y sociedad en la España del siglo XIX, libro firmado por José María López Piñero, Luis García Ballester y Pilar Faus Sevilla, con prólogo de Pedro Lain Entralgo. Madrid. Sociedad de Estudios y Publicaciones, 1964.

72 En la reunión del Comité Español, el día 14 de enero de 1963, se decidió reducir las ayudas anuales a cinco becas de libro, cada una de 4000 francos, y cinco bolsas de viaje, de 3000 francos; el objetivo de estos cambios era que fueran "tomadas en serio" por sus beneficiarios. Carta de Pierre Emmanuel a Pablo Martí Zaro, de 15 de mayo de 1963. IACF, Serie I, caja 39, f. 3. Actas de la reunión del Comité Español, el día 14 de enero de 1963, APMZ.

73 Por la similitud del tema, la beca podría haber servido para la preparación de la siguiente obra: Meditación española sobre la libertad religiosa. Barcelona. Destino, 1966.

74 Cabe suponer que dicha ayuda supuso ayudar a Joaquim Molas en su trabajo de coordinación de la Història de la literatura catalana, en cuatro volúmenes, obra dirigida en colaboración con Martí de Riquer y Antoni Comas, y publicada en Barcelona por la editorial Ariel en el año 1964.

75 Para más detalles, consúltese Glondys, 2014.

76 Vida de Don Miguel. Salamanca. Editorial Anaya, 1964. 
Pérez Díaz y Pablo Martí Zaro, para pasar dos meses en el centro parisino Centre de Sociologie Européene.

BECAS ADICIONALES:

Isidro Infante, Dionisio Ridruejo y Luis Suárez Carreño, obtenían una beca colectiva para un estudio de larga duración sobre el trasfondo de la vida en la España contemporánea, que debían llevar a cabo en colaboración con el parisino Instituto de Estudios Políticos y Sociales ${ }^{77}$.

\section{Año 1964}

BECAS DE LIBROS, cada una de 4000 francos franceses:

José Benet y Casimiro Martí, para escribir una Historia del Movimiento obrero catalán ${ }^{78}$; José Cazorla Pérez, para el libro Estructura socioeconómica de Andalucia Oriental ${ }^{79}$; José Antonio Llardent Viciana, para La lucha por la abolición de la tortura en España durante el siglo XVIII; José María Moreno Galván, para el libro La arquitectura en el espacio y en el tiempo, o bien -lo dejaba a elección del jurado-, El realismo en la pintura española, y Francesc Vallverdú, para Problemes de l'escriptor de llengua minoritaria ${ }^{80}$.

BOLSAS DE VIAJE AL EXTRANJERO PARA JÓVENES INTELECTUALES: Ramón Cajade Rey; Enrique Lite Lahiguera, Alberto Míguez; Carlos Muñiz Higuera; Lauro Olmo Gallego; Emilio Salcedo y José Arosena.

\section{Año 1965}

BECAS DE LIBROS, cada una de 4000 francos franceses:

Antonio María Badia i Margarit, para Encuesta general sobre la lengua ${ }^{81}$; José María Hernández Rubio, Gumersindo Trujillo y un grupo de expertos, para la obra colectiva Canarias ante el futuro político español; Miguel Martínez Cuadrado, para Instituciones políticas españolas 1808-1936 $6^{82}$; Daniel Sueiro, para El arte de matar ${ }^{83}, \mathrm{y}$, finalmente, Enrique Tierno Galván, para la obra Epistemología de las ciencias sociales.

\footnotetext{
77 Para las impresiones de la estancia parisina de Ridruejo, consúltese RidRUEJo, 2012.

78 Por la similitud de la temática, cabe suponer que la beca sirvió para la elaboración por ambos autores del libro Barcelona a mitjan segle XIX: el moviment obrer durant el Bienni Progressista, 1854-1856. Barcelona. Curial, 1976.

79 Factores de la Estructura socioeconómica de Andalucía Oriental. Caja de Ahorros de Granada, 1965.

80 Por la similitud del título, la beca sirvió posiblemente a confeccionar la siguiente obra: L'escriptor català $i$ el problema de la llengua. Barcelona. Edicions 62, 1968.

81 Es posible que la beca, por la similitud del tema, sirviera para la elaboración de la siguiente encuesta: Atlas lingüístic del domini català. Qüestionari. Barcelona. Universidad de Barcelona, 1965.

82 Por cierta similitud del título, la beca podría haber servido para la confección de la obra magna, en dos volúmenes y de mil páginas: Elecciones y partidos políticos de España: (1868-1931). Madrid. Taurus, 1969.

83 El arte de matar. Madrid. Alfaguara, 1968.
} 
Sin embargo, como Tierno Galván era becario directo del CLC y recibía una ayuda mensual de París $^{84}$, en su defecto recibiría esta beca Heliodoro Carpintero Capell, para su libro Pensadores españoles de hoy ${ }^{85}$.

BOLSAS DE VIAJE AL EXTRANJERO PARA JÓVENES INTELECTUALES:

José Antonio Fernández Ordóñez, para Francia; el sociólogo Carlos Moya Valgañón, a Colonia; el compositor Gonzalo de Olavide y Casenade, para Colonia; el sociólogo Enrique R. Serrano, para París, y el jurista Jesús Salvador Salvador, también para París.

\section{Años 1966-1967}

BECAS DE LIBROS, cada una de 4000 francos franceses:

Javier Muguerza, Filosofía de la significación; Luis García San Miguel, Teoría del saber jurídico (Crítica de la razón jusnaturalista) ${ }^{86}$; Carmen Martín Gaite, Macanaz y España entre dos siglos ${ }^{87}$; Rafael Tasis, Carta a un exiliat català ${ }^{88}$, y Carlos Moya Valgañón, Durkheim y la Teoría Sociológica ${ }^{89}$.

BOLSAS DE VIAJE AL EXTRANJERO PARA JÓVENES INTELECTUALES, ahora de 5000 francos cada una:

Francisco Carrillo, Raimundo Ortega Fernández y Pascual Palacios Tardez. BECAS ADICIONALES:

Beca, otorgada de forma excepcional, a Sergio Vilar y su proyecto de libro titulado Protagonistas de la España democrática.

Bolsas para intelectuales canarios, para sus desplazamientos hacia la Península, de las que nos consta que pudieron beneficiarse: Antonio Vizcaya Carpenter, Ventura Doreste, Elfidio Alonso Quintero y Anatael García Cabrera.

84 Carta de Pablo Martí Zaro a Pedro Laín Entralgo, de 29 de abril de 1965. APMZ. Al final, Tierno fue autor de un libro que guarda similitud con el tema del proyecto inicialmente becado: Conocimiento y ciencias sociales. Madrid. Tecnos, 1966.

85 Por la similitud del tema, podría considerarse que la beca sirvió para la elaboración del libro Cinco aventuras españolas: Ayala, Laín, Aranguren, Ferrarter, Marías. Madrid. Revista de Occidente, 1967.

86 Por la similitud del título, podría tratarse de la siguiente obra: Notas para una crítica de la razón jurídica. Madrid. Tecnos, 1969.

87 El Proceso de Macanaz: historia de un empapelamiento. Madrid. Moneda y Crédito, 1970.

88 Tasis murió, de forma inesperada, en París, durante el transcurso de su beca. Este ensayo inacabado, Carta a un exiliat català, fue publicado por primera vez en el libro titulado Les raons de l'exili, que recogía también otros escritos suyos, editado por Montserrat Bacardí i Francesc Foguet. Valls (Tarragona), Cossetània edicions, 2012.

89 La beca ha servido para la elaboración del artículo "La aportación funcionalista de Durkheim al diagnóstico social positivo", publicado en la Revista española de la opinión pública, 11 (enero-marzo 1968), y en la primera nota al pie del citado artículo, el autor apuntaba lo siguiente: "El presente artículo es parte de un capítulo del libro del autor: Emile Durkheim: La Sociología como ciencia positiva, de próxima publicación”. 


\section{REFERENCIAS BIBLIOGRÁFICAS}

Archivos Estadounidenses:

Archivo General del Congreso por la Libertad de la Cultura y de la Asociación Internacional por la Libertad de la Cultura. Special Collections Research Center; Regenstein Library. Universidad de Chicago.

Archivo Personal de Michael Josselson. Harry Ransom Humanities Center, Universidad de Texas.

Archivos Españoles:

Archivo Personal de Pablo Martí Zaro. Fundación Pablo Iglesias. Alcalá de Henares, Madrid.

Archivo Personal de Salvador de Madariaga. Instituto José Cornide en A Coruña.

Archivo Personal de Carlos María Bru Purón (consultado gracias a la generosidad personal del Sr. Bru Purón).

AmAT, Jordi

2009a "Grietas del realismo social: el coloquio sobre realidad y realismo en la literatura contemporánea (1963)”. Ínsula. Barcelona, no 755, pp. 19-22.

2009b "Europeísmo, Congreso por la Libertad de la Cultura y oposición antifranquista (1953-1966)". Historia y politica. Ideas, procesos y movimientos sociales. Madrid, no 21, pp. 55-72.

2010a "Tierno Galván y el Congreso por la Libertad de la Cultura". Leer. Madrid, n 214 , (julio-agosto), pp. 98-101.

2010b Els “Coloquios Cataluña-Castilla” (1964-1971). Debat sobre el model territorial de l'Espanya democràtica. Barcelona. Abadía de Montserrat.

Aubourg, Valérie - Scotт-Smith, Giles

2008 "The Transatlantic Imaginary: Constructing the Atlantic Community during the early Cold War". En Aubourg - Bossuat - Scott-Smith (eds.), European Community, Atlantic Community. París. Soleb, pp. 8-15.

BerghaHn, Volker R.

2001 America and the Cultural Cold Wars in Europe: Shepard Stone between Philanthropy, Academy, and Diplomacy. Princeton. Princeton University Press.

BERMAN, Edward H.

1983 The ideology of philanthropy: the influence of the Carnegie, Ford, and Rockefeller foundations on American foreign policy. Albany. State University of New York Press.

BEYLIN, Marek

1997 “A propos de la Fondation pour une Entraide intellectuelle européenne". L'autre Europe, Lausanne, $n^{\circ}$ 34-35, (marzo), pp. 212-222.

BIRD, Kai

1992 The chairman: John J. McCloy, the making of the American establishment. New York. Simon \& Schuster. 
Coleman, Peter

1989 The Liberal Conspiracy. The Congress For Cultural Freedom And The Struggle For The Mind Of Post-War Europe. New York. A Free Press.

Cull, Nicholas J.

2009 "Public Diplomacy before Gullion: The Evolution of a Phrase". En SNOw - TAYlor (coords.), Routledge Handbook of Public Diplomacy. New York, London. Taylor and Francis, pp. 19-23.

Delgado Gómez-Escalonilla, Lorenzo

1994 "El factor cultural en las relaciones internacionales: una aproximación a su análisis histórico". Hispania. Madrid, vol. 54, n 186, pp. 257-278.

2005 “Cooperación cultural y científica en clave política. Crear un clima favorable para las bases USA en España”. En Delgado - Elizalde (coords.), España y Estados Unidos en el siglo XX. Madrid. Consejo Superior de Investigaciones Científicas, pp. 207-243.

2009a Viento de Poniente. El Programa Fulbright en España. Madrid. Comisión Fulbright - LID Editorial - AECI.

2009b "La maquinaria de la persuasión. Política informativa y cultural de los Estados Unidos hacia España”. Ayer. Madrid, n 75, pp. 97-132.

2010 "After Franco, what? La diplomacia pública de Estados Unidos y la preparación del posfranquismo". En Martín García - Ortiz Heras (coords.), Claves internacionales en la Transición española. Madrid. Los Libros de la Catarata, pp. $99-127$.

Delgado Gómez-Escalonilla, Lorenzo - León Aguinaga, Pablo

2011 "De la primacía estratégica a la difusión del modelo americano: Estados Unidos y la España del franquismo". En Barrio Alonso - Hoyos Puente - SAaveDRA ARIAs (eds.), Nuevos horizontes del pasado: culturas politicas, identidades y formas de representación. Santander. Universidad de Cantabria, 2011, pp. 171-185.

Gemell, Giuliana (ed.)

1998 The Ford Foundation and Europe, 1950's-1970's: cross-fertilization of learning in social science and management. Bruselas. European Interuniversity Press.

2000 The 'Unacceptables': American Foundations and Refugee Scholars between the Two Wars and After. Bruselas. PIE - Peter Lang.

Gemelli, Giuliana - MAcLeod, Roy (eds.)

2003 American Foundations in Europe: Grant-Giving Policies, Cultural Diplomacy and Trans-Atlantic Relations, 1920-1980. Bruselas. PIE - Peter Lang.

GLONDYs, Olga

2009 "Zniewolony Umyst Czesława Milosza i Kongres Wolnosci Kultury”. ("El Pensamiento Cautivo de Czeslaw Milosz y el Congreso por la Libertad de la Cultura"). Zeszyty Literackie. Varsovia, no 105, pp. 217-224.

2011a "Causas y circunstancias del establecimiento del Comité Español del Congreso por la Libertad de la Cultura". En BArrio Alonso - Hoyos Puente - SAAVEDRA ArIAs (eds.), Nuevos horizontes del pasado: culturas politicas, iden- 
tidades y formas de representación. Santander. Universidad de Cantabria, CD-Rom.

2011 b "La política del 'puente' planeada desde la revista Cuadernos del Congreso por la Libertad de la Cultura". En AzNAR SOler - LóPez García (eds.), El exilio republicano de 1939 y la segunda generación. Sevilla. Renacimiento, pp. 939-949.

2012a La Guerra Fría Cultural y el Exilio Republicano Español: "Cuadernos del Congreso por la Libertad de la Cultura” (1953-1965). Madrid. Consejo Superior de Investigaciones Científicas.

2012b "Relaciones entre los comités español y portugués del Congreso por la Libertad de la Cultura en las postrimerías de las dictaduras ibéricas". En LofF - Molinero (eds.), Sociedades en cambio: España y Portugal en los años setenta. Barcelona. CEFID-UAB/IHC, CD-Rom.

2014 "Las becas del Congreso por la Libertad de la Cultura a los creadores antifranquistas: ¿un ejemplo de la intervención política en la cultura?”. En Actas del XII Congreso de la Asociación de Historia Contemporánea. Madrid. 1719 de septiembre. En prensa.

2015 “España y la Guerra Fría Cultural”. En Bengochea Tirado - Monzón Pertejo - Pérez Sarmiento (coords.), Relaciones en conflicto. Nuevas perspectivas sobre relaciones internacionales desde la historia. Valencia. Asociación de Historia Contemporánea - Universitat de Valencia, pp. 88-91.

GRACIA, Jordi

2008a Vida rescatada de Dionisio Ridruejo. Barcelona. Anagrama.

$2008 b$ "Estudio Introductorio". En RidrueJo, Escrito en España. Madrid. Centro de Estudios Políticos y Constitucionales, pp. XIII-XCIV.

GRÉmion, Pierre

1995 Intelligence de l'anticommunisme: le congrès pour la liberté de la culture à Paris: 1950-1975. París. Fayard.

1998 "The Partnership between the Ford Foundation and the Congress for Cultural Freedom in Europe". En Gemelli (ed.), The Ford Foundation and Europe, 1950's-1970's: cross-fertilization of learning in social science and management. Bruselas. European Interuniversity Press, pp. 137-165.

Guilhot, Nicolas

2006 "A network of influential friendships: the Fondation pour une entraide inte1lectualle européenne and East-West cultural Dialogue, 1957-1991”. Minerva. [Springer], $\mathrm{n}^{\mathrm{o}}$ 44, pp. 379-409.

HoCHGESCHWENDER, Michael

1998 Freiheit in der Offensive? Die Deutschen und der Kongreß für kulturelle Freiheit. Munich. Oldenbourg.

JILEK, Lubor

2009 "La Fondation pour une entraide intellectuelle européenne et le soutien aux anécédents de Solidarité". En JILEK - FLeURY (eds.), Une Europe malgré tout. Ginebra. Peter Lang, pp. 167-183. 
KeLLEY, John Robert

2009 'Between 'Take-offs' and 'Crash Landings': Situational Aspects of Public Diplomacy". En SNOW - TAYLOR (coords.), Routledge Handbook of Public Diplomacy. New York - London. Taylor and Francis, pp. 72-85.

LAVILLE, Helen - WiLford, Hugh

2006 "Preface". En Laville - Wilford (eds.), The US Government, Citizen Groups and the Cold War. The state-private network. Londres. Routledge, pp. xii-xv.

LeÓn Aguinaga, Pablo

2009 "Los canales de la propaganda norteamericana, 1945-1960". Ayer. Madrid, n 75, pp. 133-158.

LuCAS, William Scott

1999 Freedom's War: The American Crusade against the Soviet Union. New York. New York University Press.

MANGINI, Shirley

1987 Rojos y rebeldes: la cultura de la disidencia durante el franquismo. Barcelona. Anthropos.

MARTín GARCÍA, Oscar

2012-2013 "A complicated mission: the United States and Spanish Students during the Johnson Administration". Cold War History. Londres, nº 13, pp. 311-329.

Martín García, Oscar - Ortiz Heras, Manuel (coords.)

2010 Claves internacionales en la Transición española. Madrid. Los Libros de la Catarata.

McCARThY, Kathleen D.

1987 "From Cold War to Cultural Development: The International Cultural Activities of the Ford Foundation, 1950-1980". Daedalus. Cambdrige, no 116/1, pp. 93-105.

Milosz, Czeslaw

2003 Abecedario: diccionario de una vida. Madrid. Turner - FCE.

MuÑoz I LloRET, Teresa

2006 Josep M. Castellet: retrat de personatge en grup. Barcelona. Edicions 62.

NeLson, Richard - IzADI, Foad

2009 "Ethics and Social Issues in Public Diplomacy". En Snow - TAYlor (coords.),

Routledge Handbook of Public Diplomacy. New York - London. Taylor and Francis, pp. 334-351.

NiÑo, Antonio

2009a "Presentación". En NiÑo (ed.), "La ofensiva cultural norteamericana durante la Guerra Fría". Ayer. Madrid, no 75/3, pp. 13-23.

2009 b "Uso y abuso de las relaciones culturales en la política internacional". Ayer. Madrid, $n^{\circ} 75 / 3$, pp. 25-69.

2012 La Americanización de España. Madrid. Los Libros de la Catarata. 
Niño, Antonio - MonTERo, José Antonio

2012 “Introducción”. En NiÑo - MonTERo (eds.), Guerra Fría y propaganda: Estados Unidos y su cruzada cultural en Europa y América Latina. Madrid. Biblioteca Nueva, pp. 11-47.

NyE, Joseph S., Jr.,

1990 "The misleading metaphor of decline". The Atlantic Monthly. Boston, $\mathrm{n}^{\circ}$ de Marzo, pp. 86-94.

PARMAR, Inderjeet

2012 Foundations of the American Century: The Ford, Carnegie, and Rockefeller Foundations in the Rise of American Power. New York. Columbia University Press.

RIDRUEJO, Dionisio

2012 Cartas Íntimas desde el Exilio (1963-1964). Selección e introducción de Amat y Gràcia. Madrid. Fundación Banco Santander.

RODRÍGUEZ JIMÉNEZ, Francisco Javier

2007 "Haciendo amigos: intercambios educativos hispano-estadounidenses en clave política, 1959-1969”. Studia historica. Historia Contemporánea. Salamanca, $\mathrm{n}^{\mathrm{o}} 25$, pp. 339-362.

2008 “Ideología, educación o propaganda?: promoción y difusión de los estudios norteamericanos en Salamanca, 1939-1959". Studia historica. Historia Contemporánea. Salamanca, nº 26, pp. 243-271.

2010 "Controversias de la Guerra Fría cultural: una reflexión desde lo ocurrido en torno a los 'American Studies', 1945-1975”. Revista Complutense de Historia de América. Madrid, no 36, pp. 79-102.

Santisteban Fernández, Fabiola de

2009 “El desembarco de la Fundación Ford en España”. Ayer, Madrid, n 75/3, pp. 159-191.

SAUNDERS, Frances Stonor

1999 Who Paid the Piper?: CIA and the Cultural Cold War. London. Granta. (Traducción española: La CIA y la Guerra fría cultural. Madrid. Debate. 2001).

Scotт-Smith, Giles

2002 The Politics of Apolitical Culture. London. Routledge.

2006 "Building a Community around the Pax Americana. The US government and exchange programs during the 1950s". En LAVILLE - WILFORD (eds.), The US Government, Citizen Groups and the Cold War. The state-private network. London. Routledge, pp. 83-99.

2008a "Identity and Informal Empire: American Public Diplomacy and the Promotion of an Atlantic Community in the 1950s". En Aubourg - Bossuat - ScotTSмiтн (eds.), European Community, Atlantic Community. Paris. Soleb, pp. 74-91.

2008b "Mapping the Undefinable: Some Thoughts on the Relevance of Exchange Programs within International Relations Theory". The Annals of the American Academy of Political and Social Science. Philadelphia, nº 616, pp. 173-195. 
2010 "The Congress for Cultural Freedom: Constructing an Intellectual Atlantic Community". En Mariano (ed.), Defining the Atlantic Community: Culture, Intellectuals, and Policies in the mid-20th Century, vol. 4. London. Routledge, pp. 132-145 (Atlantic Studies).

2011 "Europe Americanized? Popular Reception of Western Cold War Propaganda in Europe". Re.de Cold War History, vol. 11, n 1, (february), pp. 1-98. En H-Diplo Article Review Roundtable, Vol. XIII, 4, en (enero de 2015):http://hnet.msu.edu/cgi-bin/logbrowse.pl?trx=vx\&list=h-diplo\&month=1109\&wee $\mathrm{k}=\mathrm{e} \& \mathrm{msg}=\mathrm{eCzhtIDXS} / \mathrm{n} 5 \mathrm{edSrk} \% 2 \mathrm{BeFOA} \& u s e r=\& \mathrm{pw}=$

SNOw, Nancy

2009 "Rethinking Public Diplomacy". En SNOw - TAYLOR (coords.), Routledge Handbook of Public Diplomacy. New York - London. Taylor and Francis, pp. 3-11.

TREVERTON, George F.

1987 Covert Action. The Limits of Intervention in the Postwar World. New York. Basic Books.

WARNER, Michael

1995 "Origins of the Congress for Cultural Freedom, 1949-50". Studies in Intelligence. Washington, $\mathrm{n}^{\mathrm{o}} 38$. En https://www.cia.gov/library/center-for-thestudy-of-intelligence/kent-csi/docs/v38i5a10p.htm (consulta: 08/2009).

WILFORD, Hugh

2003 The CIA, the British left and the Cold War: calling the tune? Londres. F. Cass. 2008 Mighty Wurlitzer: how the CIA played America. Cambridge. Harvard University Press. 